\title{
The effects of narrow band middle infrared radiation in enhancing the antitumor activity of paclitaxel
}

\author{
Supplemental File
}

\section{Dosages of paclitaxel for HeLa cells}

Human cervical cancer HeLa cells were seeded at a density of $5 \times 10^{4}$ in 12-well culture plates. The cells were cultured in RPMI 1640 medium (Invitrogen, USA) supplemented with $10 \%$ fetal bovine serum (Invitrogen, USA) overnight. The old medium was removed, and the HeLa cells were then treated with paclitaxel at concentrations of $0,5,10$, and $20 \mathrm{nM}$ for 48 hours.

The cell viability of cells was determined using a Scepter ${ }^{\mathrm{TM}}$ cell counter, which uses the Coulter principle to accurately discern cell diameter at sub-micron resolutions. Scepter ${ }^{\mathrm{TM}}$ Software Pro was used to perform data analysis, as shown in Fig. S1. The cell viability of cancer cells treated with paclitaxel at concentrations of 5 , 10 , and $20 \mathrm{nM}$ were $85.3,74.2$, and 26.5 , respectively. Therefore, $10 \mathrm{nM}$ paclitaxel was considered a moderate dose with which to evaluate the $50 \%$ minimum inhibitory concentration in this study. 


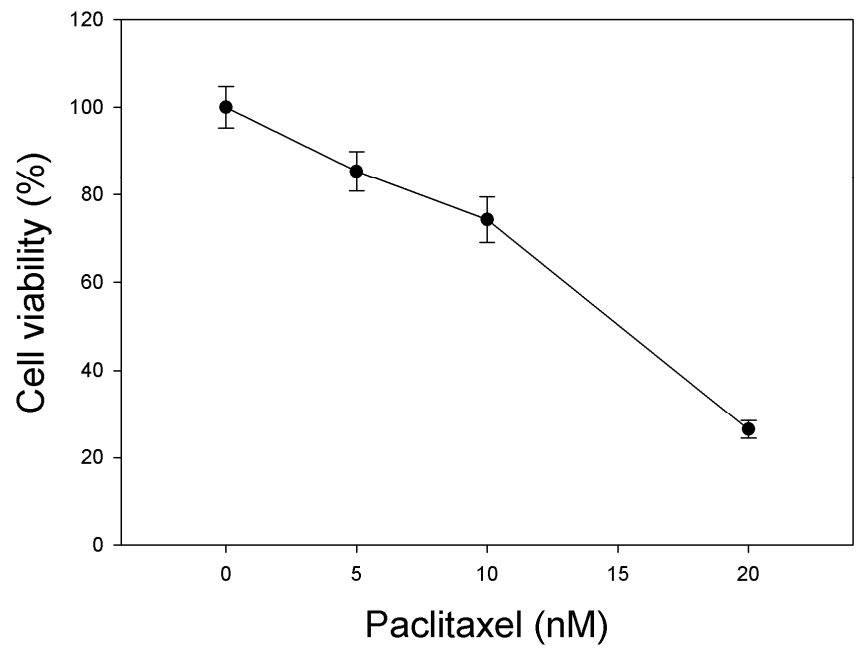

Figure S1 Cell viability of cells treated with various dosages of paclitaxel over a period of 48 hours. Data was obtained from three independent experiments. The cell viability of cells was defined as the control group (untreated), set to $100 \%$. Data are presented as the mean \pm SD of the percentage of cells. 
Monitoring the temperature of the medium irradiated by MIR for $\mathbf{4 8}$ hours

While the culture medium irradiated by MIR at the intensity of $2.5 \sim 3 \mathrm{~mW} / \mathrm{cm}^{2}$

for 48 hours, the local temperature of the culture medium remained unchanged at 36.5

$\pm 1^{\circ} \mathrm{C}$, as shown in Fig. S2.

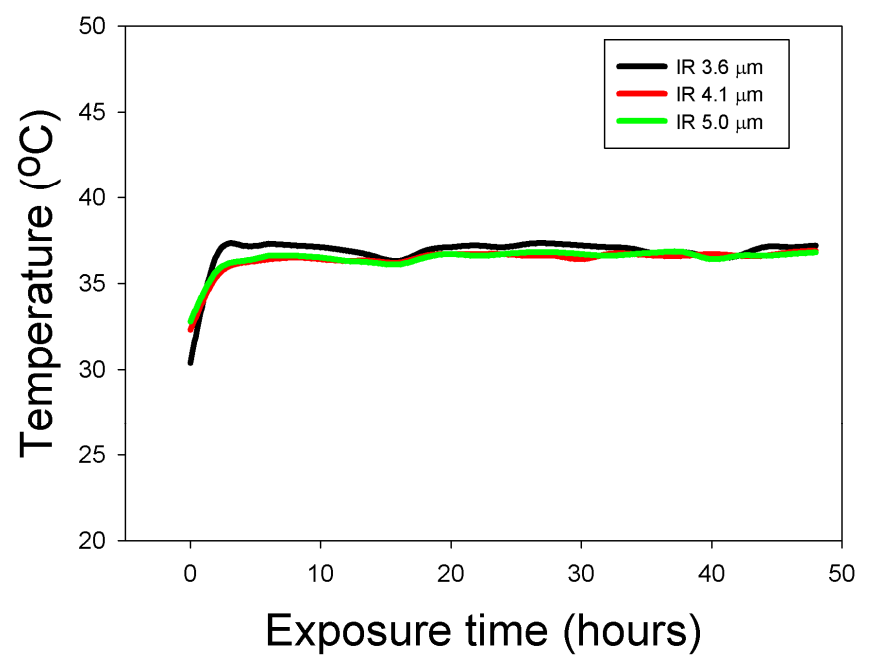

Figure S2 Time course of local MIR-induced changes in temperature in the

culture medium as measured using a calibrated thermal couple over a period of 48 hours. 